\title{
Nanoscale
}

Cite this: Nanoscale, 2013, 5, 6552

\section{Incorporation of small BN domains in graphene during CVD using methane, boric acid and nitrogen gas}

\author{
George Bepete, ${ }^{\text {ab }}$ Damien Voiry, ${ }^{c}$ Manish Chhowalla, ${ }^{c} Z^{2}$ ivayi Chiguvare $\dagger^{b}$ \\ and Neil J. Coville*a
}

\begin{abstract}
Chemical doping of graphene with small boron nitride (BN) domains has been shown to be an effective way of permanently modulating the electronic properties in graphene. Herein we show a facile method of growing large area graphene doped with small BN domains on copper foils using a single step CVD route with methane, boric acid powder and nitrogen gas as the carbon, boron and nitrogen sources respectively. This facile and safe process avoids the use of boranes and ammonia. Optical microscopy confirmed that continuous films were grown and Raman spectroscopy confirmed changes in the electronic structure of the grown BN doped graphene. Using XPS studies we find that both B and N can be substituted into the graphene structure in the form of small $\mathrm{BN}$ domains to give a $\mathrm{B}-\mathrm{N}-\mathrm{C}$ system. A novel structure for the BN doped graphene is proposed.
\end{abstract}

Received 5th April 2013

Accepted 27th May 2013

DOI: $10.1039 / c 3 n r 01699 d$

www.rsc.org/nanoscale

\section{Introduction}

Since the discovery of atomically thick graphene in $2004,{ }^{1}$ it has been considered as one of the most promising candidates for future electronic devices due to its excellent electronic properties $^{2,3}$ and versatile application possibilities in transparent electronics. ${ }^{4-7}$ The absence of a band gap in graphene however limits its properties for application in electronic devices and reproducible practical procedures that open a band gap in graphene would widen its applicability. One way of achieving this is by doping. ${ }^{8}$ Different methods to make doped graphene can introduce these modifications and tune the properties of graphene to render graphene a highly customizable material as has been achieved with carbon nanotubes. ${ }^{9}$ Making graphene a hole conductor involves the use of electron withdrawing dopants, whilst electron donating dopants are used to make it an electron conductor. Two types of graphene doping have been widely investigated, namely surface transfer doping ${ }^{10}$ and chemical doping. ${ }^{11}$ Doping has been achieved by the use of chemical species or an electric field. ${ }^{12}$ The surface transfer doping methods have been used successfully to modify charge carriers in graphene but the shortcoming of the approach is that the doping is temporary and the doped graphene

${ }^{a} D S T / N R F$ Centre of Excellence in Strong Materials and Molecular Sciences Institute, School of Chemistry, University of the Witwatersrand, WITS 2050, Johannesburg, South Africa. E-mail: neil.covile@wits.ac.za; Fax: +27117176749

${ }^{b} D S T / N R F$ Centre of Excellence in Strong Materials and Material Physics Research Institute, School of Physics, University of the Witwatersrand, WITS 2050, Johannesburg, South Africa

${ }^{c}$ Materials Science and Engineering, Rutgers University, 607 Taylor Road, Piscataway, New Jersey 08854, USA

$\uparrow$ Current address: Renewable Energy and Energy Efficiency Institute, Polytechnic of Namibia, 13 Storch Street, Private bag 13388, Windhoek, Namibia. is difficult to integrate into functional devices. Permanent doping has been achieved in graphene by chemical doping using B for p-type graphene and $\mathrm{N}$ for $\mathrm{n}$-type graphene..$^{13} \mathrm{~A}$ wide range of precursor materials have been reported to incorporate nitrogen or boron into graphene. ${ }^{14-17}$

Several theoretical studies have shown that simultaneous incorporation of $\mathrm{B}$ and $\mathrm{N}$ in graphene is thermodynamically possible yielding small planar hexagonal boron nitride (h-BN) domains in graphene and most importantly that this process achieves band gap modulation in graphene. ${ }^{18,19}$ The band gap opening in graphene, due to doping with small BN domains, has been attributed to the breaking of localized symmetry. ${ }^{20}$ The tunable electronic properties of graphene material containing BN make this material likely to be useful in electronic devices, composites, energy conversion and storage. ${ }^{21}$ Indeed, a CVD method has recently been used to grow BN doped graphene on a copper foil using $\mathrm{Ar} / \mathrm{H}_{2}$, methane and ammonia borane gases. ${ }^{22}$ This method produced graphene domains alloyed with discrete large BN domains.

Here we demonstrate a facile, safe process for the chemical vapor deposition synthesis of $\mathrm{BN}$ doped graphene on copper using methane, boric acid powder and nitrogen gas. We show that $\mathrm{B}$ and $\mathrm{N}$ are incorporated and that the $\mathrm{N}$ is bonded with the carbon within the graphene structure to make a continuous BN graphene material. Small units of $\mathrm{BN}$ in graphene, i.e. one $\mathrm{B}$ surrounded by three $\mathrm{N}$ and singly occurring hexagonal BN rings containing three $\mathrm{B}$ atoms and six $\mathrm{N}$ atoms are formed. Three of the $\mathrm{N}$ atoms in the hexagonal rings are also bonded to the carbon of the graphene. We provide a simple reproducible experimental method to synthesize large area graphene doped with small BN domains which can be used to make high quality BN doped graphene for possible applications in nanoelectronic devices. 


\section{Experimental section}

\subsection{Materials}

BN doped graphene was synthesized by a chemical vapor deposition (CVD) method. Copper foil (25 $\mu \mathrm{m}$ thick, Alpha Aesar) was used as the catalyst in this study. ${ }^{23} \mathrm{~A} 1 \mathrm{~cm} \times 2 \mathrm{~cm}$ copper foil was inserted into the centre of a cylindrical quartz tube reactor $(22 \mathrm{~cm} \times 100 \mathrm{~cm})$. A copper envelope containing $300 \mathrm{mg}$ boric acid powder was inserted into the quartz tube reactor $4 \mathrm{~cm}$ behind the copper foil as shown in Fig. 1. The reactor was evacuated to 30 Torr. A $7 \% \mathrm{H}_{2}$ in $\mathrm{N}_{2}\left(\mathrm{H}_{2}-\mathrm{N}_{2}\right)$ gas mixture (Air Gas, batch analyzed grade) was introduced into the reactor at $80 \mathrm{sccm}$ whilst the vacuum was kept at 30 Torr for a further 15 minutes. The reactor was then heated to $995^{\circ} \mathrm{C}$ under vacuum. The reactor was held at $995{ }^{\circ} \mathrm{C}$ for a further 30 minutes after which methane gas (Air products, Ultrahigh purity) was also introduced at $20 \mathrm{sccm}$. The reaction was allowed to proceed for 20 minutes. The methane flow was stopped and the reactor was cooled under the $\mathrm{H}_{2}-\mathrm{N}_{2}$ gas at $80 \mathrm{sccm}$. Numerous experiments were conducted to optimize the separation between the boric acid container and the copper foil catalyst. The $4 \mathrm{~cm}$ separation distance was found to be the optimal distance for quality graphene growth to take place in the presence of a boric acid source. Methane (20 sccm) and $\mathrm{H}_{2}-\mathrm{N}_{2}$ gas $(80 \mathrm{sccm})$ without boric acid was also used to produce undoped graphene using the same procedure. The graphene was transferred onto a silicon substrate with a $300 \mathrm{~nm}$ silicon oxide layer $\left(\mathrm{SiO}_{2} / \mathrm{Si}\right)$ as reported in ref. 23. In summary, $5 \mathrm{~mm} \times 5 \mathrm{~mm}$ copper foil squares were cut from the $1 \mathrm{~cm} \times 2 \mathrm{~cm}$ copper foil catalyst used and poly(methyl methacrylate) (PMMA) (Mico Chem) was spin coated onto the surface of the copper square on a spin coater (3000 rpm). The copper was then etched away from the doped graphene/PMMA layers ( 3 hours) in a $1 \mathrm{M}$ solution of $\mathrm{FeCl}_{3}$ contained in a Petri dish. After all the copper had been etched away, the graphene/PMMA was left floating in the $\mathrm{FeCl}_{3}$ solution and was then washed several times in a $1 \mathrm{M}$ solution of $\mathrm{HCl}$, followed by washing in water. Lastly the graphene/PMMA was attached to a cleaned $\mathrm{SiO}_{2} / \mathrm{Si}$ substrate and was left to dry for 2 hours in air at ambient temperature. The PMMA was removed from the graphene by dissolving the PMMA in acetone. This was achieved by placing the PMMA/graphene on the $\mathrm{SiO}_{2} / \mathrm{Si}$ in a Petri dish containing acetone which was left standing for 15 minutes. The acetone was decanted and replaced by fresh

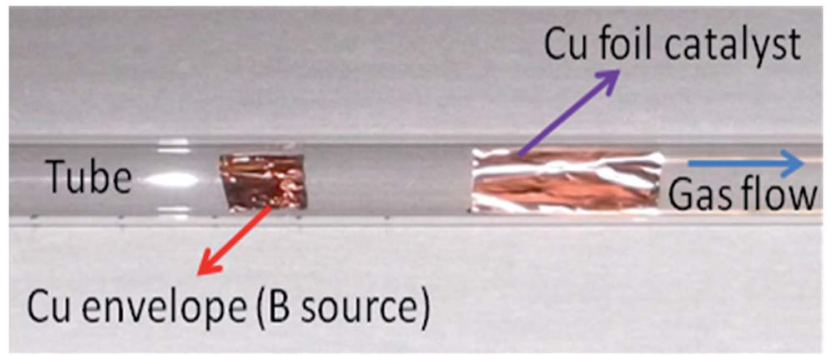

Fig. 1 Cylindrical quartz tube reactor showing the inserted copper envelope containing boric acid (boron source) placed $4 \mathrm{~cm}$ before the flat copper foil catalyst used for graphene growth. acetone, and the process was repeated 3 times. Lastly the graphene was washed in methanol (to ensure complete removal of PMMA/acetone residues) and left to dry in air under ambient conditions.

\subsection{Characterization}

The doped and undoped graphene samples were characterized on $\mathrm{SiO}_{2} / \mathrm{Si}$ substrates unless otherwise stated. Optical images of the graphene were recorded using an optical microscope. Surface morphology and graphene thickness characterization studies were conducted by tapping-mode atomic force microscopy (AFM) using a Dimension 3100 from Veeco. Morphological characterization of the $\mathrm{BN}$ doped graphene was carried out on graphene transferred onto plain copper grids using a Technai $\mathrm{G}^{2}$ spirit TEM at $120 \mathrm{kV}$. Raman spectra were measured on an InVia Raman microscope (Reinshaw) at an excitation wavelength of $514 \mathrm{~nm}$. X-ray photoelectron spectroscopy (XPS) measurements were performed with a Thermo Scientific $\mathrm{K}$-Alpha spectrometer. All spectra were recorded using an $\mathrm{Al} \mathrm{K \alpha}$ microfocussed monochromatized source (1486.6 eV) with a resolution of $0.6 \mathrm{eV}$. The spot size was $400 \mu \mathrm{m}$ and the operating pressure was $5 \times 10^{-9} \mathrm{~Pa}$.

\section{Results and discussion}

Fig. 2a shows the optical image of the pristine graphene and Fig. $2 \mathrm{~b}$ shows the optical image of $\mathrm{BN}$ doped graphene that was transferred onto $\mathrm{SiO}_{2} / \mathrm{Si}$ substrates. The images of both the undoped and the $\mathrm{BN}$ doped graphene reveal a large area, uniform and continuous material. The pristine graphene in Fig. 2a has a light pink colour while the $\mathrm{BN}$ doped graphene (Fig. 2b) is dark pink in colour. The colour contrast suggests that the $\mathrm{BN}$ doped graphene could be a single or double layer graphene. Fig. 2c and d show TEM images of a continuous BN doped graphene material on a plain $\mathrm{Cu}$ grid. The small dark spots observed are due to residual $\mathrm{Cu}$ particles; the holes are due to imperfections in the graphene layer which develop during the transfer process. AFM imaging data revealed a continuous film of BN doped graphene with wrinkles (Fig. 2e) which resulted from the transfer process of the graphene onto the $\mathrm{SiO}_{2} / \mathrm{Si}$ substrate. The section analysis of the $\mathrm{BN}$ doped graphene shown in Fig. 2e revealed a uniform material with a thickness between 1.0 and $1.4 \mathrm{~nm}$ indicating that the material was at most a double layer graphene. ${ }^{24}$ In summary, both AFM and TEM analyses indicate that the $\mathrm{BN}$ doped graphene is uniform and of large area (Fig. 2).

Raman spectra of pristine and $\mathrm{BN}$ doped graphene were taken from five different regions of both the doped and undoped graphene samples. Fig. 3 shows the comparison of the Raman spectra of one measurement from both the pristine and BN doped graphene. The Raman spectrum of pristine CVD graphene shows three peaks $\left(1347,1585\right.$ and at $\left.2686 \mathrm{~cm}^{-1}\right)$ representing the $\mathrm{D}, \mathrm{G}$ and the $2 \mathrm{D}$ bands respectively (Table 1 ). ${ }^{25}$ Compared to the $\mathrm{G}$ and the $2 \mathrm{D}$ bands the $\mathrm{D}$ band has a very small intensity showing that the graphene is of high quality. ${ }^{25}$ The ratio between the intensity of the $\mathrm{G}$ to that of the $2 \mathrm{D}$ band 


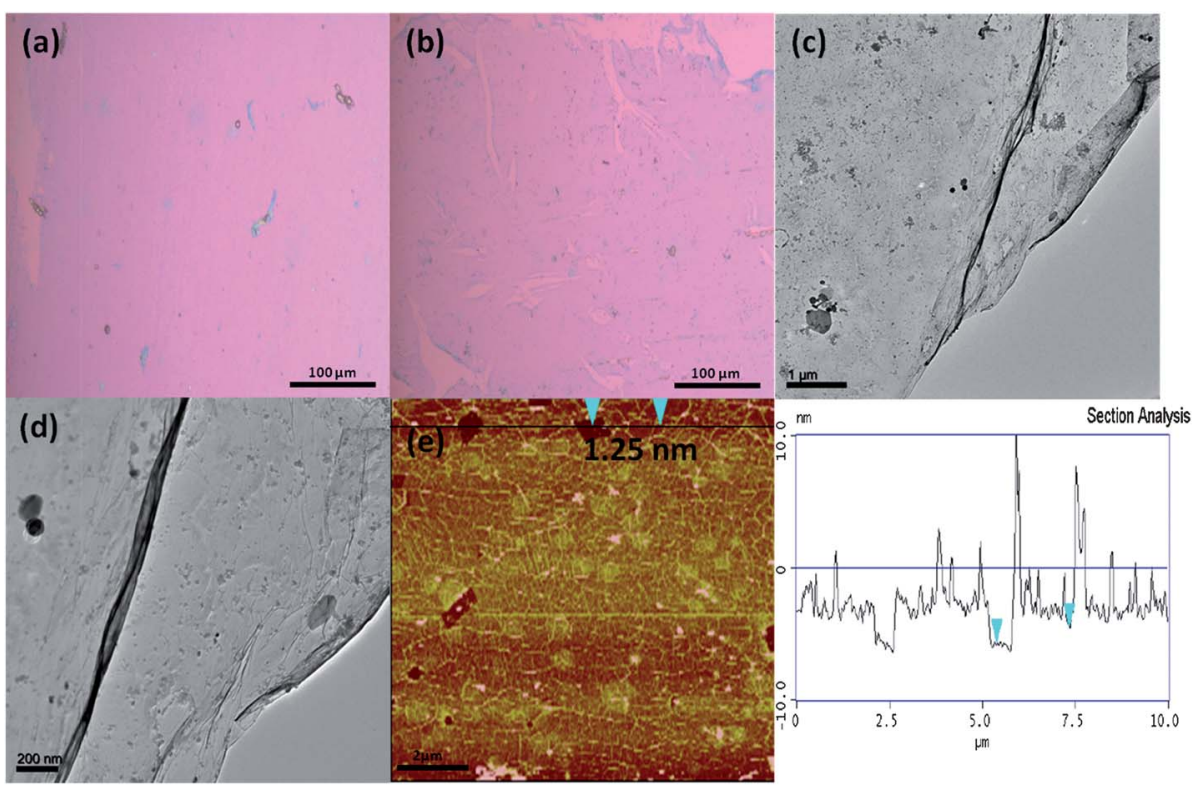

Fig. 2 Graphene and $\mathrm{BN}$ doped graphene films grown on $\mathrm{Cu}$ using boric acid and nitrogen gas. (a) Optical images of pristine graphene transferred onto a $\mathrm{SiO} / \mathrm{Si}$ substrate. (b) Optical image of $\mathrm{BN}$ doped graphene transferred onto a $\mathrm{SiO}_{2} / \mathrm{Si}$ substrate. (c) Low-magnification TEM image of BN doped graphene on a plain CU TEM grid showing a continuous graphene film. (d) High-magnification TEM image of BN doped graphene on a plain Cu grid showing small particles of Cu and Fe remaining after the etching process. (e) AFM image of BN doped graphene showing wrinkled graphene and (f) AFM section analysis of BN graphene showing an average film thickness of $1.25 \mathrm{~nm}$.

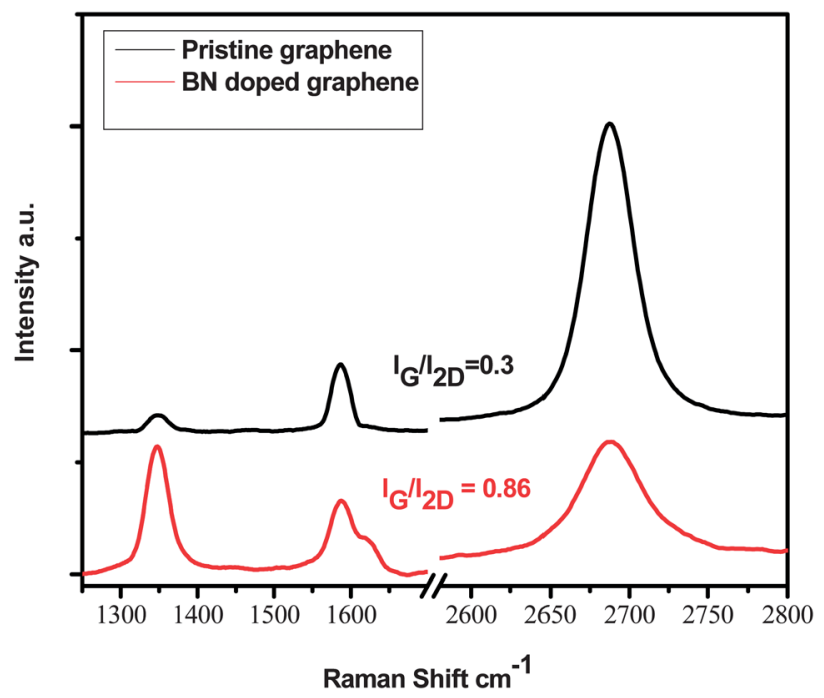

Fig. 3 Raman spectra of pristine graphene and BN doped graphene synthesized using the CVD method on copper.

$\left(I_{\mathrm{G}} / I_{2 \mathrm{D}}\right)$ is $c a .0 .3$ which suggests that the graphene has properties similar to that of a single layer graphene. ${ }^{24}$ The Raman spectrum of the BN doped graphene also showed three peaks

Table 1 Raman peak positions of pristine graphene and BN doped graphene synthesized by the CVD method on copper

\begin{tabular}{lllll}
\hline Raman shift & $\mathrm{D}\left(\mathrm{cm}^{-1}\right)$ & $\mathrm{G}\left(\mathrm{cm}^{-1}\right)$ & $\mathrm{D}^{*}\left(\mathrm{~cm}^{-1}\right)$ & $2 \mathrm{D}\left(\mathrm{cm}^{-1}\right)$ \\
\hline Pristine graphene & 1347 & 1585 & - & 2686 \\
BN graphene & 1341 & 1589 & 1623 & 2690
\end{tabular}

(1341, 1589 and $2690 \mathrm{~cm}^{-1}$ ) again representing the $\mathrm{D}, \mathrm{G}$ and the 2D bands respectively (Table 1 ).

The slight upshift of the G and 2D peaks of the doped graphene is associated with chemical doping into the graphene structure. ${ }^{26}$ The $\mathrm{D}$ band of the doped graphene showed a slight downshift. The doping is further corroborated by a shoulder on the $\mathrm{G}$ peak, also known as the $\mathrm{D}^{*}$ peak, observed at $1623 \mathrm{~cm}^{-1}$. This split in the G peak of graphene has been reported previously by several authors and has been attributed to localized symmetry breaking in graphene, ${ }^{27-29}$ as found in BN doped graphene. ${ }^{22}$ The $I_{\mathrm{G}} / I_{2 \mathrm{D}}$ ratio of the BN doped graphene is 0.86 , and the intensity of the $2 \mathrm{D}$ band is diminished in the $\mathrm{BN}$ doped graphene.

XPS data were recorded on the pristine and BN doped graphene. All spectra were recorded using an $\mathrm{Al} \mathrm{K} \alpha$ microfocussed monochromatized source $(1486.6 \mathrm{eV})$ with a resolution of $0.6 \mathrm{eV}$. The spot size was $400 \mu \mathrm{m}$ and the operating pressure was $5 \times 10^{-9} \mathrm{~Pa}$. XPS data for pristine graphene revealed the presence of $\mathrm{C}$ and a small amount of $\mathrm{O}$ (not shown). The doped graphene by contrast showed peaks in the 400,190 and $284 \mathrm{eV}$ regions that correspond to $\mathrm{N}, \mathrm{B}$ and $\mathrm{C}$ atoms respectively (Fig. 4). The atomic percentage of C, N and B in the sample was $98.0 \%, 1.38 \%$ and $0.62 \%$ respectively. The atomic percentage of the $\mathrm{N}$ and $\mathrm{B}$ dopants could be increased, but this was accompanied by an increase in the oxygen content and poor quality of the BN doped graphene that was produced.

Fig. 4a shows the N1s spectrum of BN doped graphene and reveals only a single peak at $399.8 \mathrm{eV}$. Since pure hexagonal boron nitride (h-BN) ${ }^{30}$ and $\mathrm{BN}$ doped graphene with discrete domains of BN alloyed with graphene ${ }^{22}$ give peaks at $398.1 \mathrm{eV}$, these types of structures can be ruled out in this new material. The peak at $399.8 \mathrm{eV}$ is close to, but different from, the reported 

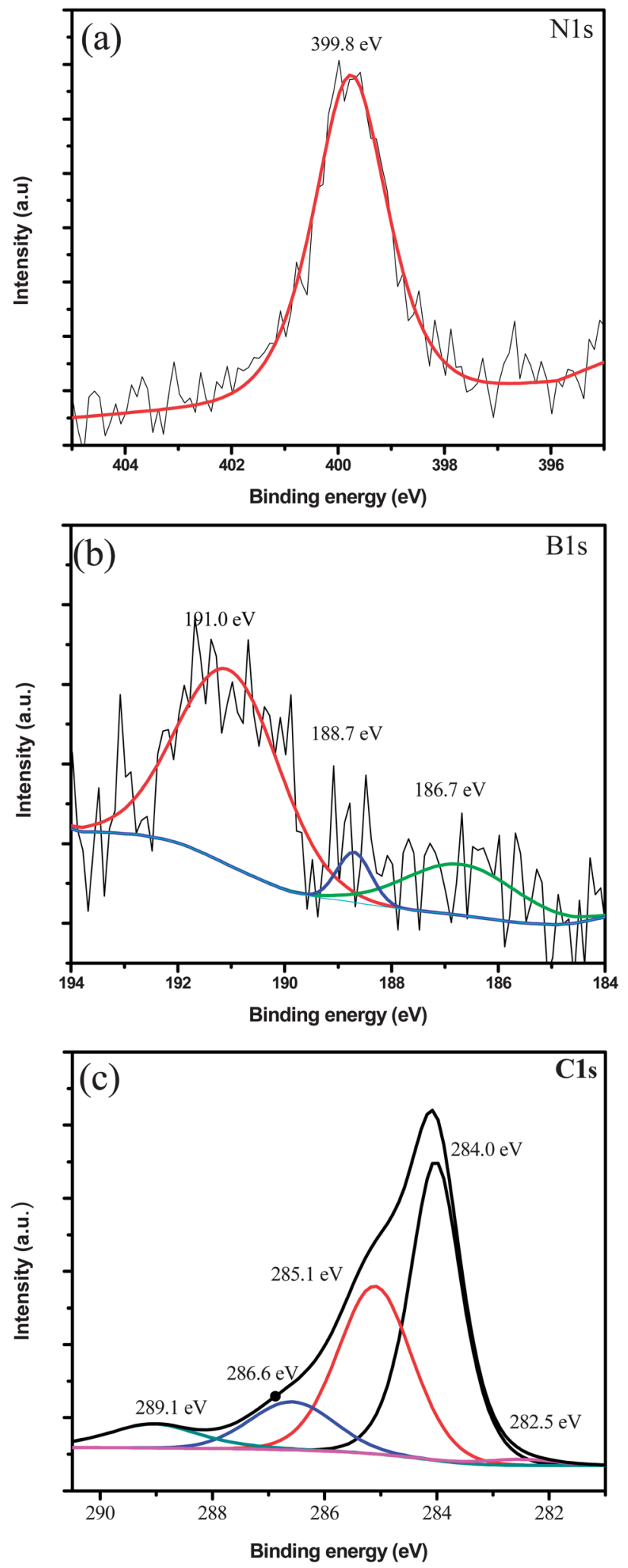

Fig. 4 XPS spectra showing the (a) N1s, (b) B1s, and (c) C1s core levels obtained from BN doped graphene.

XPS peak energy of $\sim 401 \mathrm{eV}$ for graphitic/quaternary $\mathrm{N}$ in graphene. $^{31}$ The N1s peak position lies more toward the high binding energy region of a $\mathrm{C}-\mathrm{N}$ bond. This suggests that there are more $\mathrm{C}-\mathrm{N}$ bonds around a single $\mathrm{N}$ compared to $\mathrm{B}-\mathrm{N}$ bonds. This is possible in a case where $\mathrm{N}$ is bonded to one $\mathrm{B}$ atom and two $\mathrm{C}$ atoms. These data suggest that the $\mathrm{BN}$ is not in the form of discrete domains (Fig. 6c) but is part of the extended graphene structure in the form of small $\mathrm{BN}$ domains shown in Fig. $6 a$ and $b .^{20}$

The B1s profile shown in Fig. 4b suggests that several B species are present and incorporated within the doped graphene product. The three peaks at $c a .191 .0,188.7$ and $186.7 \mathrm{eV}$ having different intensities indicate three B containing species with different concentrations. The large B1s peak at $191.0 \mathrm{eV}$ can be associated with a boron atom linked to a nitrogen atom (BN structure). ${ }^{32,33}$ This is consistent with $\mathrm{BN}$ incorporation into graphene. The two boron species in lower concentrations, compared to the $\mathrm{B}$ in the $\mathrm{BN}$, could correspond to $\mathrm{BC}_{3}$ at $188.7 \mathrm{eV}$ (ref. 34 and 35) and to $\mathrm{B}_{4} \mathrm{C}$ at $186.7 \mathrm{eV}$ (ref. 36) suggesting that $\mathrm{C}-\mathrm{B}$ bonds are also present in the new material. However B-C bonds are very few meaning that, under the reaction conditions we have in this case (methane, boric acid and nitrogen gas), $\mathrm{B}-\mathrm{N}$ formation is more favourable than $\mathrm{B}-\mathrm{C}$ formation.

The C1s spectrum of the BN doped graphene (Fig. 4c) shows five peaks after deconvolution. The peak at $284.0 \mathrm{eV}$ corresponds to $\mathrm{sp}^{2}$ hybridized carbon (graphitic carbon) from the undoped region of the graphene material. ${ }^{37}$ The peak at $285.1 \mathrm{eV}$ can be associated with $\mathrm{sp}^{2}$ hybridized carbon bonded to nitrogen ${ }^{38}$ and to carbon with defects. ${ }^{39}$ The two peaks associated with $\mathrm{sp}^{2}$ hybridized carbon bonded to nitrogen and to carbon with defects overlap at $285.1 \mathrm{eV}$ to form one peak. The peak at $285.1 \mathrm{eV}$ likely arises from graphene domain edges and defects. The smaller peak at lower binding energy $(282.5 \mathrm{eV})$ can be associated with $\mathrm{B}-\mathrm{C}$ bond formation. The higher binding energy peaks at $c a$. 286.6 and $289.1 \mathrm{eV}$ are attributed to the formation of $\mathrm{C}-\mathrm{O}$ bonds. ${ }^{40}$

Fig. 5 shows the comparison of the C1s spectra of the pristine graphene with those of $\mathrm{BN}$ doped graphene. The C1s spectrum of pristine graphene has a more symmetrical shape

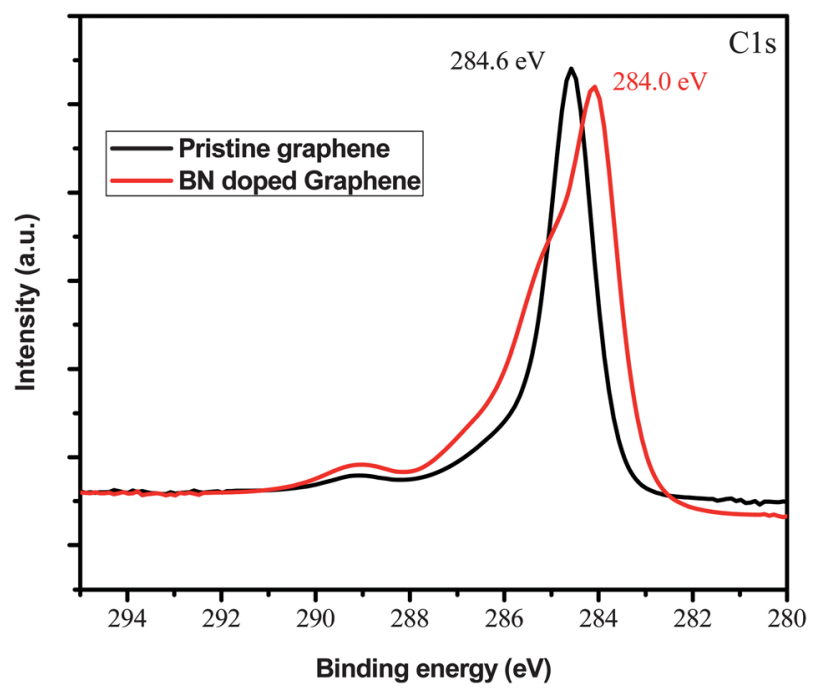

Fig. 5 C1s core level spectra of pristine graphene and BN doped graphene. 
and is very sharp when compared to the C1s spectra of the doped graphene. XPS analysis showed a downshift of $0.6 \mathrm{eV}$ and broadening of the C1s peak after doping with BN. The downshift in the C1s peak of the doped material suggests that the material is a p-type semiconductor as was observed in doped p-type semiconducting carbon nanotubes. ${ }^{41}$ Experimental studies have shown that carbon films doped with both $\mathrm{B}$ and $\mathrm{N}$ exhibit p-type semiconducting behavior. ${ }^{42}$ Ambipolar semiconducting behavior was reported in a h-BNC material which contained discrete domains of graphene and h-BN. ${ }^{21}$ Analysis of the atomic composition of $\mathrm{B}$ and $\mathrm{N}$ atoms in our $\mathrm{BN}$ doped graphene showed that the $\mathrm{B} / \mathrm{N}$ ratio was between 0.5 and 0.3 , i.e., $\mathrm{N}$ was in excess in the graphene. This is possible because the $\mathrm{N}$ source in this reaction was nitrogen gas and this was in excess compared to the B from boric acid.

Fig. 6 shows three possible types of $\mathrm{BN}$ structures in the graphene matrix. Fig. 6a shows a $\mathrm{BN}$ species with a $\mathrm{B} / \mathrm{N}$ ratio of 0.33 and Fig. $6 \mathrm{~b}$ shows an h-BN structure with a $\mathrm{B} / \mathrm{N}$ ratio of 0.5 . The $\mathrm{B} / \mathrm{N}$ ratio expected for Fig. $6 \mathrm{c}$, which shows larger $\mathrm{BN}$ domains, is close to 1 . The data hence suggest that small $\mathrm{BN}$ domains have been incorporated within the graphene matrix but not in large discrete $\mathrm{BN}$ domains.

We propose a mechanism for the formation of small $\mathrm{BN}$ domains within the extended graphene structure. Upon heating, $\mathrm{H}_{3} \mathrm{BO}_{3}$ in the copper container melts $\left(171^{\circ} \mathrm{C}\right)$ and volatilizes above $300{ }^{\circ} \mathrm{C}$. The $\mathrm{N}_{2}$ carrier gas carries the $\mathrm{H}_{3} \mathrm{BO}_{3}$ to the copper foil (catalyst). Here the $\mathrm{H}_{3} \mathrm{BO}_{3}$ decomposes to form $\mathrm{B}_{2} \mathrm{O}_{3}$. Addition of $\mathrm{CH}_{4}$ at $995{ }^{\circ} \mathrm{C}$ results in the formation of reactive carbon species (eqn (1)). ${ }^{43}$ Reaction of $\mathrm{C}$ with $\mathrm{B}_{2} \mathrm{O}_{3}$ on the copper catalyst surface generates $\mathrm{B}-\mathrm{C}$ species. However in the presence of $\mathrm{N}_{2}$, the $\mathrm{B}-\mathrm{C}$ species are stabilized and form $\mathrm{BN}$ species in the graphene matrix (eqn (2)). The two reactions shown in eqn (1) and (2) take place on the copper surface. Reaction (2) is initiated by reaction (1). A similar mechanism has been used to explain the synthesis of BN doped single walled carbon nanotubes. ${ }^{44}$ Formation of $\mathrm{BN}$ in a graphene oxide material using graphene oxide material and $\mathrm{B}_{2} \mathrm{O}_{3}$ required a temperature of $1500{ }^{\circ} \mathrm{C} .{ }^{33}$ In our case the reaction took place at $995{ }^{\circ} \mathrm{C}$ using the inert $\mathrm{N}$

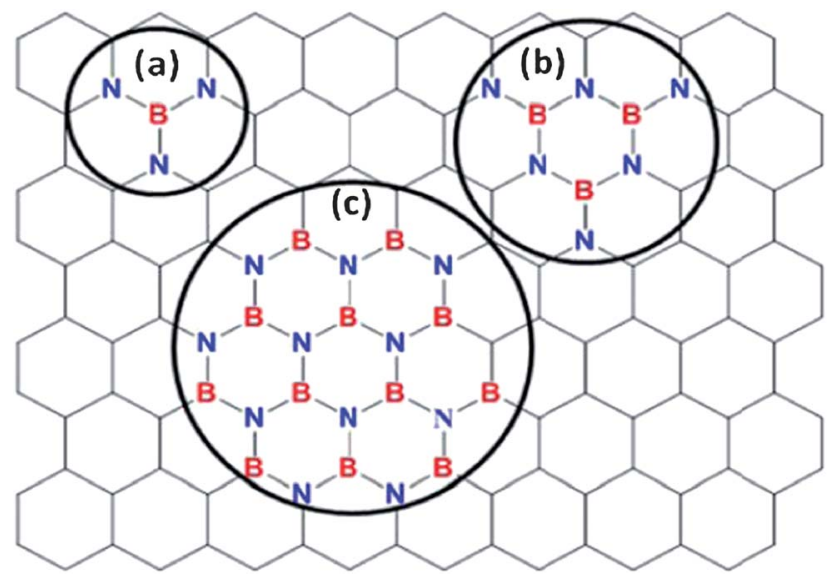

Fig. 6 Atomic model of the possible BN species incorporated in BN doped graphene (a) BN with $\mathrm{N}$ bonded to 2 carbon atoms, (b) h-BN with the $\mathrm{N}$ bonded to one or two carbon atoms and (c) h-BN domains in the graphene matrix. source, $\mathrm{N}_{2}$ gas. The reaction can also be performed at low temperatures $<1000{ }^{\circ} \mathrm{C}$ if the more reactive $\mathrm{NH}_{3}$ replaces the inert $\mathrm{N}_{2} \cdot{ }^{\mathbf{4 3 , 4 5}}$

$$
\begin{gathered}
\mathrm{CH}_{4}(\mathrm{~g})+\mathrm{H}_{2}(\mathrm{~g}) \rightarrow \mathrm{C}(\mathrm{s})+\mathrm{H}_{2}(\mathrm{~g}) \\
\mathrm{B}_{2} \mathrm{O}_{3}(\mathrm{~s})+3 \mathrm{C}(\mathrm{s})+\mathrm{N}_{2}(\mathrm{~g}) \rightarrow \mathrm{BN}(\mathrm{s})+3 \mathrm{CO}(\mathrm{g})
\end{gathered}
$$

\section{Conclusions}

In summary, we have synthesized large area graphene incorporating small BN species by a facile and safe process avoiding the use of boranes and ammonia. Raman analysis reveals formation of monolayer (or few layer) BN doped graphene. XPS revealed that several $\mathrm{B}$ bonding species were incorporated into graphene with the main product being the small BN domains. The $\mathrm{N}$ of the $\mathrm{BN}$ is bonded to carbon forming $\mathrm{B}-\mathrm{N}-\mathrm{C}$ systems, showing that we managed to grow continuous $\mathrm{BN}$ containing graphene in which BN species were incorporated in the graphene structure. This remarkable finding has led us to synthesize large area graphene incorporating small $\mathrm{BN}$ domains. The method is a simple one. Raman data revealed an additional $\mathrm{D}^{*}$ band in the $\mathrm{BN}$ doped graphene that confirmed possible band gap opening by graphene symmetry breaking. The results presented here are highly relevant to the application of graphene in nano-optoelectronic devices.

\section{Acknowledgements}

This work was supported financially by the NRF, the DST/NRF Center of Excellence in Strong Materials and the University of the Witwatersrand. MC would like to acknowledge funding from the NSF IGERT (0903661) program. GB would like to acknowledge Dr Johanna Bernstein and Professor Eric Garfunkel for facilitating the IGERT matching support from Rutgers University for his visit to Rutgers University. DV acknowledges funding from Rutgers University. We are in debt to Dr Manoko Maubane and Thuto Makgato for their kind help with TEM and AFM respectively.

\section{Notes and references}

1 K. S. Novoselov, A. K. Geim, S. V. Morozov, D. Jiang, Y. Zhang, S. V. Dubonos, I. V. Grigorieva and A. A. Firsov, Science, 2004, 306, 666-669.

2 A. H. Castro Neto, F. Guinea, N. M. R. Peres, K. S. Novoselov and A. K. Geim, Rev. Mod. Phys., 2009, 81, 109-162.

3 C. Stamfer, S. Fringes, J. Guttinger, F. Molitor, C. Volk, B. Terres, J. Dauber, S. Engels, S. Schnez, A. Jacobsen, S. Droscher, T. Ihn and K. Ensslin, Front. Phys., 2011, 6, 271-293.

4 S. Ghosh, I. Calizo, D. Teweldebrhan, E. P. Pokatilov, D. L. Nika, A. A. Balandin, W. Bao, F. Miao and C. N. Lau, Appl. Phys. Lett., 2008, 92, 151911.

5 Y. Zhu, S. Murali, W. Cai, X. Li, J. W. Suk, J. R. Potts and R. S. Ruoff, Adv. Mater., 2010, 22, 3906-3924. 
6 S. S. Li, K. H. Tu, C. C. Lin, C. W. Chen and M. Chhowalla, ACS Nano, 2010, 4, 3169-3174.

7 X. Wang, L. Zhi and K. Müellen, Nano Lett., 2008, 8, 323327.

8 H. Liu, Y. Liu and D. J. Zhu, J. Mater. Chem., 2011, 21, 33353345.

9 J. M. Schnorr and T. M. Swager, Chem. Mater., 2011, 23, 646657.

10 W. Chen, S. Chen, D. C. Qi, X. Y. Gao and A. T. S. Wee, J. Am. Chem. Soc., 2007, 129, 10418-10422.

11 H. Miao, S. Tongay, M. K. Petterson, K. Berke, A. G. Rinzler, B. R. Appleton and A. F. Hebard, Nano Lett., 2012, 12, 27452750.

12 K. F. Mak, C. H. Lui, J. Shan and T. F. Heinz, Phys. Rev. Lett., 2009, 102, 256405.

13 L. S. Panchakarla, K. S. Subrahmanyam, S. K. Saha, A. Govindaraj, H. R. Krishnamurthy, U. V. Waghmare and C. N. R. Rao, Adv. Mater., 2009, 21, 4726-4730.

14 C. Zhang, L. Fu, N. Liu, M. Liu, Y. Wang and Z. Liu, Adv. Mater., 2011, 23, 1020-1024.

15 Y. Wang, Y. Shao, D. W. Matson, J. Li and Y. Lin, ACS Nano, 2010, 4, 1790-1798.

16 Z. H. Sheng, H. L. Gao, W. J. Bao, F. B. Wang and W. H. Xia, J. Mater. Chem., 2012, 22, 390-395.

17 S. Suzuki and H. Hibino, Mater. Sci. Eng., B, 2012, 177, 233238.

18 P. P. Shinde and V. Kumar, Phys. Rev. B: Condens. Matter Mater. Phys., 2011, 84, 125401.

19 B. Xu, Y. H. Lu, Y. P. Feng and J. Y. Lin, J. Appl. Phys., 2010, 108, 073711-073717.

20 X. Fan, Z. Shen, A. Q. Liu and J. Kuo, Nanoscale, 2012, 4, 2157-2165.

21 Y. Lin and J. W. Connell, Nanoscale, 2012, 4, 6908-6939.

22 L. Ci, L. Song, C. Jin, D. Jariwala, D. Wu, Y. Li, A. Srivastava, Z. F. Wang, K. Storr, L. Balicas, F. Liu and P. M. Ajayan, Nat. Mater., 2010, 9, 430-435.

23 X. Li, W. Cai, J. An, S. Kim, J. Nah, D. Yang, R. Piner, A. Velamakanni, I. Jung, E. Tutuc, S. K. Banerjee, L. Colombo and R. Ruoff, Science, 2009, 324, 1312-1314.

24 C. Mattevi, H. Kim and M. Chhowalla, J. Mater. Chem., 2011, 21, 3324-3334.

25 A. C. Ferrari, J. C. Meyer, V. Scardaci, C. Casiraghi, M. Lazzeri, F. Mauri, S. Piscanec, D. Jiang, K. S. Novoselov, S. Roth and A. K. Geim, Phys. Rev. Lett., 2006, 97, 187401.

26 C. Casiraghi, S. Pisana, K. S. Novoselov, A. K. Geim and A. C. Ferrari, Appl. Phys. Lett., 2007, 91, 233108.
27 X. Dong, Y. Shi, Y. Zhao, D. Chen, J. Ye, Y. Yao, F. Gao, Z. Ni, T. Yu, Z. Shen, Y. Huang, P. Chen and L. Li, Phys. Rev. Lett., 2009, 102, 135501.

28 R. Yang, Q. S. Huang, X. Chen, G. Y. Zhang and H. J. Gao, J. Appl. Phys., 2010, 107, 034305.

29 J. Lee, K. S. Novoselov and H. S. Shin, ACS Nano, 2011, 5, 608-612.

30 C. Guimon, D. Gonbeau, G. Pfister-Guillouzo, O. Dugne, A. Guette, R. Naslain and M. Lahaye, Surf. Interface Anal., 1990, 16, 440-445.

31 J. O. Hwang, J. S. Park, D. S. Choi, J. Y. Kim, S. H. Lee, K. E. Lee, Y. H. Kim, M. H. Song, S. Yoo and S. O. Kim, ACS Nano, 2012, 6, 159-167.

32 K. S. Park, D. Y. Lee, K. J. Kim and D. W. Moon, Appl. Phys. Lett., 1997, 70, 315-317.

33 T. W. Lin, C. Y. Su, X. Q. Zhang, W. Zhang, Y. H. Lee, C. W. Chu, H. Y. Lin, M. T. Chang, F. R. Chen and L. J. Li, Small, 2011, 8, 1384-1391.

34 W. Cermignani, T. E. Paulson, C. Onneby and C. G. Pantano, Carbon, 1995, 33, 367-374.

35 L. G. Jacobsohn, R. K. Schulze, M. E. H. Maia da Costa and M. Nastasi, Surf. Sci., 2004, 572, 418-424.

36 E. A. Il'inchik, V. V. Volkov and L. N. Mazalov, J. Struct. Chem., 2005, 46, 523-534.

37 E. Moreau, F. J. Ferrer, D. Vignaud, S. Godey and S. Wallart, Phys. Status Solidi A, 2010, 207, 300-303.

38 Y. Shao, S. Zhang, M. H. Engelhard, G. Li, G. Shao, Y. Wang, J. Liu, I. A. Aksayc and Y. Lin, J. Mater. Chem., 2010, 20, 74917496.

39 Z. Q. Luo, J. Z. Shang, S. H. Lim, D. H. Li, Q. H. Xiong, Z. X. Shen, J. Y. Lin and T. Yu, Appl. Phys. Lett., 2010, 97, 233111.

40 C. Morant, P. J. Prieto, J. Bareño, M. Sanz and E. Elizalde, Thin Solid Films, 2006, 515, 207-211.

41 H. Z. Geng, K. K. Kim, C. Song, N. T. Xuyen, S. M. Kim, K. A. Park, D. S. Lee, K. H. An, Y. S. Lee, Y. Chang, Y. J. Lee, J. Y. Choi, A. Benayad and Y. H. Lee, J. Mater. Chem., 2008, 18, 1261-1266.

42 M. O. Watanabe, S. Itoh, K. Mizushima and T. Sasaki, J. Appl. Phys., 1995, 78, 2880.

43 P. Ammendola, R. Chirone, L. Lisi, G. Ruoppolo and G. Russo, J. Mol. Catal. A: Chem., 2007, 266, 31-39.

44 W. L. Wanga, J. Q. Bia, W. X. Suna, H. L. Zhua, J. J. Xua, M. T. Zhaoa and Y. J. Bai, Mater. Chem. Phys., 2010, 122, 129-132.

45 J. Thomas, N. E. Weston and T. E. O'Connor, J. Am. Chem. Soc., 1962, 84, 4619-4622. 